\title{
Exposure to Air Pollution and Risk of Cancer in Children- A Case Control Study
}

\section{Maral Mazloumi Tabrizi ${ }^{1}$, Seyed Ahmad Hosseini ${ }^{2}$, Azim Akbarzadeh Khiyavi ${ }^{3}$}

${ }^{1}$ Department of Toxicology and Pharmacology, Pharmaceutical Sciences Branch, Islamic Azad University, Tehran, Iran. ${ }^{2}$ Department of Occupational Health, Faculty of Health Sciences, University of Shahid Beheshti (MC), Tehran, Iran. ${ }^{3}$ Pasteur of Iran in Department nanobiechnology, Tehran, Iran.

\begin{abstract}
Introduction:Children are one of the easiest affected group from environmental deterioration and detrimental factors, Due to their biological and behavioral differences. And childhood cancer has considered as one of the most common cause of death in children in developing countries. Exposure to some environmental factors during childhood can increase the risk of cancer in the offspring. Methods: This study aimed to evaluate the role of living in the pollutant regions and exposure to cigarette or hookah smoke on the incidence of cancer in children. This case-control study was considered 22 cases and 100 controls, under 10 years, who was born and lived in pollutant regions of Tehran in 2014-2015. Results and Disscotion: Regarding the important risk factors: familial background of underlying diseases or cancer. However, in this ages, the Familial background of cancer is considered as the most crucial risk factor of the incidence of cancer in children ( $\mathrm{P}=0.000, \mathrm{OR}=7.639$, CI 95\% 4.230-13.794). Moreover, the second most significant item is live in regions with polluted air $(\mathrm{P}=0.019, \mathrm{OR}=4.222$, CI 95\% 1.172-15.211).
\end{abstract}

Keywords: Childhood cancer- air pollution- environmental factors- smoking

Asian Pac J Cancer Biol, 2 (1), 13-15

\section{Introduction}

With the public's growing, concerns about public health would increase in the next decade. The major new concern is about cancer, especially in children. [1]. Children are particularly susceptible to the effects of air pollution. Because of the tendency in children to spend more time outdoors, such as playing sports, so they have more exposure to the air pollutants. They breathe through their mouths, bypassing the filtering effects of the nasal passages and allowing pollutants to travel deeper into the lungs. They have a large lung surface area relative to their weight and inhale relatively more air, in comparison with adults. Also, indoor air pollution is important. Environmental tobacco smoke (ETS) is often cited as a key factor in indoor air quality and public health. ETS exposure is a significant avoidable risk factor for respiratory diseases among children [2]. Some controversial evidence estimated the role of paternal residential and occupational
Submission Date: 11/14/2016 Acceptance Date: 01/25/2017

Corresponding Author:

Dr. Maral Mazloumi Tabrizi and Seyed Ahmad Hosseini

Department of Toxicology and Pharmacology, Pharmaceutical Sciences Branch, Islamic Azad University, Tehran, Iran.

Department of Occupational Health, Faculty of Health Sciences, University of Shahid Beheshti (MC), Tehran, Iran.

Email: ma.mazlumi@gmail.com, ahm.hosseini@gmail.com 


\section{Materials and Methods}

\section{Population study}

A case-control study was conducted on 22 diagnosed cancer and 100 normal children under 10 years who was born and live in Tehran. Pathological reports were used for evaluating cancer. Lack of access to the parents, birth and living out of Tehran and non-smoking parents were considered as exclusion criteria for cases and controls.

\section{Definition of environmental resources}

Air Quality Index: AQI is an index for reporting daily air quality. It tells us how clean or polluted our air is, and what associated health effects might be a concern for us. EPA calculates the AQI for five major air pollutants regulated by the Clean Air Act: ground-level ozone, particle pollution (also known as particulate matter), carbon monoxide, sulfur dioxide, and nitrogen dioxide. For each of these pollutants, EPA has established national air quality standards to protect public health. Each category corresponds to a different level of health concern. The six levels of health concern and what they mean are:

"Good" AQI is 0 to 50. "Moderate" AQI is 51 to 100. "Unhealthy for Sensitive Groups" AQI is 101 to 150. "Unhealthy" AQI is 151 to 200. "Very Unhealthy" AQI is 201 to 300. "Hazardous" AQI greater than 300. In this study, we considered some regions of Tehran that the AQI was upper than 101, for the majority of days in the year, and we estimated these areas as pollutant regions of the city.

Polycyclic aromatic hydrocarbons: PAHs are an environmentally ubiquitous class of compounds that are found during incomplete combustion of organic substances. Several PAHs have been classified as probable human carcinogens [7]. In the general population, the major source of exposure is tobacco smoke [8], with diet and exposure to fossil fuel combustion by-products contributing to cumulative exposure [9]. Although there is strong evidence for the relationship between PAH exposure and lung, skin, and bladder cancer in humans
[10]. The results supported the concept that the PAH in cigarette smoke must interact with other components in order to exert a tumorigenic effect [11]. We tried to consider the effects of PAHs on the incidence of cancer in children. In this study, we considered some people who smoke more than five cigarettes per day as a smoker.

\section{Definition of background variables}

We have designed a specific questionnaire, including The region of birth and living, parental ages, parental career, parental and personal history of disorders, familial history of cancer, and smoking status of parents.

\section{Definition of underlying diseases}

Underlying disorders, especially those that chronically impair immune host response (For example hematologic malignancies) increase the incidence of infection [12].

In this work, we estimated some types of disorders as underlying diseases: Cardiovascular disease, Diabetes, Depression, Anxiety, Epilepsy, and Addiction.

\section{Statistical Methods}

Values expressed as the mean standard deviation or percent per population. Moreover, student T-test used to assess associations between parametric variables. SPSS 16 used to calculate relative risks and odds ratios. On the other hand, a significant risk factor is reported when the odds ratio in cases is $>1$, the probability values is $<0.05$, the $5 \%$ confidence interval of the true odds ratio is $>1$, When the odds ratio in controls is $<1$, if the probability values is $<0.05$ and when the $5 \%$ confidence interval of the true odds ratio is $<1$.

\section{Results}

Familial background of cancer is considered as the most crucial risk factor of the incidence of cancer in children $(\mathrm{P}=0.000, \mathrm{OR}=7.639$, CI 95\% 4.230-13.794).

The second important item is life in regions with polluted air $(\mathrm{P}=0.019, \mathrm{OR}=4.222$, CI 95\% 1.172-15.211). The third

Table 1 . Comparison of Familial and Environmental Risk Factors Between Cancer Cases and Controls

\begin{tabular}{|c|c|c|c|c|c|c|}
\hline \multirow[t]{2}{*}{ Characteristics } & \multirow[t]{2}{*}{ Case $(n=22)$} & \multirow[t]{2}{*}{ Control $(n=100)$} & \multirow[t]{2}{*}{ P-Value } & \multirow[t]{2}{*}{ OR } & \multicolumn{2}{|l|}{ CI $95 \%$} \\
\hline & & & & & Lower & upper \\
\hline History of underlying disease & & & 0.014 & 2.597 & 1.244 & 5.422 \\
\hline Yes & $8(36.3 \%)$ & $14(14 \%)$ & & & & \\
\hline No & $14(63.63 \%)$ & $86(86 \%)$ & & & & \\
\hline \multicolumn{7}{|l|}{ Familial background of cancer } \\
\hline Yes & $10(45.45 \%)$ & $2(2 \%)$ & 0 & 7.639 & 4.23 & 13.794 \\
\hline No & $12(54.54 \%)$ & $99(99 \%)$ & & & & \\
\hline \multicolumn{7}{|l|}{ Live in regions with polluted air } \\
\hline Yes & $3(13.63 \%)$ & $40(40 \%)$ & 0.019 & 4.222 & 1.172 & 15.211 \\
\hline No & $19(86.36 \%)$ & $60(60 \%)$ & & & & \\
\hline \multicolumn{7}{|l|}{ Parent's smoking } \\
\hline Yes & $13(59.09 \%)$ & $22(22 \%)$ & $<0.001$ & 3.59 & 1.689 & 7.631 \\
\hline No & $9(40.90 \%)$ & $78(78 \%)$ & & & & \\
\hline
\end{tabular}


risk factor of this type of disease in children is parent's smoking $(\mathrm{P}=<0.001, \mathrm{OR}=3.590$, CI 95\% 1.689-7.631). History of underlying disease is considered as the other significant item in this study $(\mathrm{P}=0.014, \mathrm{OR}=2.597, \mathrm{CI}$ $95 \% 1.244-5.422)$.

\section{Discussion}

This work tried to find the possible risk factors of cancer in children who are residents in polluted areas and children with smoker parents, in Tehran.

Some epidemiological studies have examined the prevalence of cancer and its possible risk factors in different states of Iran. While there are clear differences in the incidence rates of cancer-based on age, residence, and type of this disease, in these studies.

Due to the higher levels of air pollution, soil pollution and smoker residences(outdoor and indoor pollutions) in Tehran, we focused on parental environmental exposures. We considered here some most significant causes and the specific role of childhood exposure to smoking. Furthermore, living in regions with polluted air, in these children is considered as the second important factor $(\mathrm{P}=0.019, \mathrm{OR}=4.222$, CI 95\% 1.172-15.211).

We observed in the present study, the other important factor is parent's smoking $(\mathrm{P}=<0.001, \mathrm{OR}=3.590, \mathrm{CI}$ 95\% 1.689-7.631).

Although, a genetic component for cancer occurrence in several case families has suggested in the same study (Zierhut $\mathrm{H}$ et al. 2012).

In Conclusion, this study has considered exposure to some environmental factors, especially living in pollutant regions through the parents or children, continuous exposure to cigarette or hookah smoke, as well as the role of the other risk factors of cancer which we described previously. In this work, we confirmed a new risk factor for cancer in children.

\section{References}

1. Bailey HD AB, de Klerk NH et al. Exposure to diagnostic radiological procedures and the risk of childhood acute lymphoblastic leukemia. Cancer Epidemiol Biomarkers Prev., 2010. 2897-909. p.

2. Bailey HD, Fritschi L, Infante-Rivard C, Glass DC, Miligi L, Dockerty JD, et al. Parental occupational pesticide exposure and the risk of childhood leukemia in the offspring: findings from the childhood leukemia international consortium. International journal of cancer. 2014;135(9):2157-72.

3. Bailey HD, Fritschi L, Metayer C, Infante-Rivard C, Magnani C, Petridou E, et al. Parental occupational paint exposure and risk of childhood leukemia in the offspring: findings from the Childhood Leukemia International Consortium. Cancer Causes Control. 2014;25(10):1351-67.

4. Deziel NC, Rull RP, Colt JS, Reynolds P, Whitehead TP, Gunier RB, et al. Polycyclic aromatic hydrocarbons in residential dust and risk of childhood acute lymphoblastic leukemia. Environmental research. 2014;133:388-95.

5. D'Angelo C, Costantini E, Kamal MA, Reale M. Experimental model for ELF-EMF exposure: Concern for human health. Saudi journal of biological sciences. 2015;22(1):75-84.
6. Bailey HD MM, Greenop KR et al. Paternal intake of folate and vitamins B6 and B12 before conception and risk of childhood acute lymphoblastic leukemia. . Cancer Causes Control,. (2014).(25(12), ):1615-25.

7. Hashemizadeh H, Boroumand H, Noori R, Darabian M. Socioeconomic status and other characteristics in childhood leukemia. Iranian journal of pediatric hematology and oncology. 2013;3(1):182-6.

8. Hauri D, Spycher B, Huss A, Zimmermann F, Grotzer M, von der Weid N, et al. Domestic radon exposure and risk of childhood cancer: a prospective census-based cohort study. Environmental health perspectives. 2013;121(10):1239-44.

9. Marshall GM, Carter DR, Cheung BB, Liu T, Mateos MK, Meyerowitz JG, et al. The prenatal origins of cancer. Nature reviews Cancer. 2014;14(4):277-89.

10. Janghorbani M, Piraei E. Association between air pollution and preterm birth among neonates born in Isfahan, Iran. Journal of research in medical sciences : the official journal of Isfahan University of Medical Sciences. 2013;18(10):87581.

11. Lupo PJ, Dietz DJ, Kamdar KY, Scheurer ME. Geneenvironment interactions and the risk of childhood acute lymphoblastic leukemia: exploring the role of maternal folate genes and folic Acid fortification. Pediatric hematology and oncology. 2014;31(2):160-8.

12. Metayer C, Milne E, Dockerty JD, Clavel J, Pombo-deOliveira MS, Wesseling C, et al. Maternal supplementation with folic acid and other vitamins and risk of leukemia in offspring: a Childhood Leukemia International Consortium study. Epidemiology (Cambridge, Mass). 2014;25(6):81122.

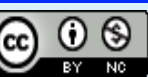

This work is licensed under a Creative Commons AttributionNon Commercial 4.0 International License. 